\title{
On Taoism Management Thought
}

\author{
Xin $\mathrm{He}^{1, \mathrm{a}^{*}}$ \\ ${ }^{1}$ Institute of Taoism and Religious Culture, Sichuan University, \\ Chengdu, Sichuan Province, China \\ a48987255@qq.com
}

\begin{abstract}
Keywords: Taoism; Management; Taiping (peace and tranquility); An (peace)
\end{abstract}
\begin{abstract}
Taoism is born in the land of China and is a native religion of the Chinese nation. Its growth fully absorbs the nutrients of Chinese traditional culture, so it also affects all aspects of Chinese traditional culture. Taoism occupies an important position in China. Since the founding of the people's Republic of China, the invasion of western culture had been strong. Taoism was regarded as superstition and had not been paid enough attention. Taoist research was almost at a standstill state. But, with the improvement of China's comprehensive national strength and public awareness, Taoist research has been restored and achieved gratifying results. Now scholars' research has involved many aspects of Taoism, but from the perspective of management, the study on Taoist management thoughts is very weak. The miscellaneous and various perspectives of Taoism itself is one aspect factor, and the unclear scope and definition of the Taoist management thought is the important reason that hinders the research of Taoism management thought. This paper aims to clarify the research scope and definition of Taoist management.
\end{abstract}

\section{Introduction}

Taoism was born in China and is a native religion of the Chinese nation. Its growth has fully absorbed the nutrients of the traditional Chinese culture, so it also affects all aspects of Chinese traditional culture. Taoism follows Lao Tzu's thought of "supreme charity likes water", it emphasizes the merit of acting like water. Therefore, many ancient Chinese thought wisdom was integrated with Taoism, and the classics were retained. In the long history, Taoism culture gradually penetrated into all fields of social China, and had a huge impact. Today, the way of thinking and behavior of the Chinese is till effected Taoism culture somehow. As Mr. Lu Xun once said: "the root of Chinese is totally rooted in Taoism,...... starting from this point, many problems can be smoothly done or easily solved." Mr. Lu Xun had this exclamation after investigation on the Taoist connotation, it also indicates the fundamental position of Taoism in Chinese traditional culture.

After the founding of the PRC, in quite a long period of time, due to the strong invasion of western culture, the management science was dominated by Western management. Since the reform and opening up, especially since twenty-first Century, China's economy, political, military and other aspects have gradually stepped into the right track. In this context, the intellectuals gradually have "cultural confidence", and the study of Chinese management is gradually increasing in the field of management. A great deal of outstanding achievements have been emerged in the management thought research of Confucianism, Taoism, Legalists and Mohist. The study of Taoist management thought has also been on the right track.

\section{Starting Point of Study on Taoism Management Thought}

There are few studies on the "Taoist management thought" in academic circles. Only a few papers have been published. However, as the content of "Taoism management thought" involves "Lao Tzu management thought, Taoist management thought, China (Orient) management philosophy" and so on, there are more or less related research results related to "Taoist management thought".

However, there are obvious shortcomings in this kind of research results: firstly, the focus of attention is mainly on the management system of Taoism, especially the management system of Taoism at a certain time. For example, the doctoral thesis of Lin Xi Lang: Research on Management 
System of Taoism in Tang Dynasty. Secondly, there is little correlation between scholars' research. They have been studied from the aspects of system, politics, palace and ethics. However, from their research point of view, they haven't integrated previous research results. Thirdly, the research on the philosophy of Taoism is still very weak, although there is a topic study, the doctoral thesis of Yan Shijiao: Management Philosophy of Taoism, but in fact, it was based on "political management philosophy".

In addition, there are many research monographs on "Chinese management", most of which involve the management ideas of Lao Tzu or Taoism, but there is no thematic discussion.

In a word, the current research results have not only focused on the areas involved, so there are some shortcomings, and there are also many problems that have not been studied in the areas that have been involved. This leaves much room for us to continue studying Taoist management thought.

\section{Definition of Taoism Management Thought}

It is necessary to define the research scope of "Taoism management thought" for the study of Taoism management thought. The first is to distinguish between "Taoist management thought" and "Taoism management thought". Taoist mainly refers to the pre Qin Classical Taoist school represented by Laozi and Chuang-tzu. Taoist management thought is based on the study of management thoughts based on classic Taoist classics such as Tao Te Ching and Chuang-tzu. Taoism was formed by the formation of Wudoumi Taoism and Taiping Taoism, it is a religious organization that has been popular to the present. There is a place where the Taoist thought of Taoism and the Taoist thought of management overlap, but more of them are their own theoretical system. Secondly, it is necessary to make a distinction and definition of management science, management philosophy and management thought. The category of culture is more than thought, the category of thought is greater than philosophy, and the category of philosophy is greater than science. The management science focuses on how to complete a management activity, involving five aspects of "plan, organization, personnel, leadership and control", and it has systematic theoretical support in every aspect. Management philosophy is a metaphysical methodology guiding management science. Management thought is a theoretical system that integrates management science and management philosophy.

Though the research on Taoist management thought is basically related to several aspects of Taoist management. The perspectives of the research involve several respective directions, such as the management of the view of the palace, the management of the political ethics, the management of the commandment of the precepts, the philosophy of the Taoism of Lao Tzu and so on. So far, there has not been a systematic treatise on the Taoist thought of Taoism, and no one has even made a clear definition of the "Taoist management thought".

The Taoist management ideas include two major parts of the Taoist management science and the Taoist management philosophy. Based on the mode of thinking of "those metaphysical are called Tao and those physical are called Qi", Taoist management science belongs to the category of "Qi". Taoist management philosophy belongs to the category of "Tao". With regard to metaphysical "management science", western modern management starts from this point, and explains management as "designing and maintaining a good environment, so that people can achieve the goal in a group state efficiently." The development of modern western management science has been very perfect, which can serve as a reference perspective for this book. But as "physical" management science is not the whole management idea, management philosophy is also an important part of management thought.

Taoism has abundant ideological resources and research results in forming a good group environment, helping individuals achieve effective goals, and defining efficiency and goals. But the contribution of Taoism management thought is not limited to this, it starts from Tao to elaborate the deep view of "managing" the country and the family, the society and the palace view, the individual and the Taoism, the life and the nature, these are the key points of the Taoist management thought need to be combed, read and made out key points. Specifically, Taoist management philosophy is 
based on Taoist management philosophy and formed through its later development and evolution. Taoist management science is composed of Taoist country \& family management, Taoist life management, Taoist Palace management, Taoist ecological management and so on.

There are several core points in the study of Taoist management thoughts. First of all, "the perspective of management and the level of thought" is the dual relationship that we must pay attention to in the study of Taoist management thoughts. Secondly, we should pay attention to avoid the study of "physical" Taoist management methods or management skills, and to avoid the study of the "metaphysical" Taoist management philosophy.

\section{The core of Taoism Management Thought: "An Ping Tai"}

"An Ping Tai" originates from chapter 35 of Tao Te Ching: When everyone knows Tao, then the world will be in peace and tranquility"[1]. Someone explains An as "so, therefore", for example, Mr. Chen Guying holds this view. But in fact, "An Ping Tai" are notional words, An means safe, Ping means Peace, and Tai means Calm, Enro, for example, the edition FuYi, Annotations, the edition Suze, the edition Lin Xiyi and so on.

Why is the core of Taoism management thought: "An Ping Tai"? First of all, let's see Tao, the

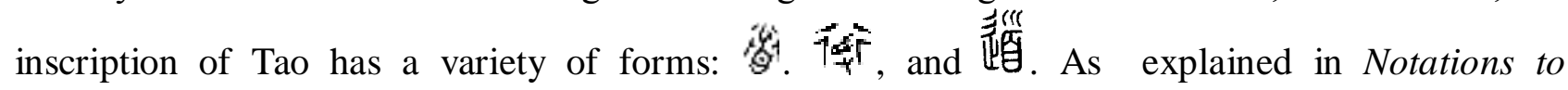
frequently-used characters: Tao is a combination of the meanings of "walking, acting and nature". In the ancient times, people believed that there was a clan spirit and evil spirits in the region of other clans, which would incur catastrophe, so when they entered other regions, they must hold the head of the alien to cleanse evil disaster. When it was natural clean, it was called as Tao to guide direction. The large needle with a handle could be used as worship tool, when it was punched to earth, the evil spirits on land could be cleaned. The road cleaned by such way was called "Tu" [2].

From the etymology of Tao, in ancient times, human society was a clan society, each with its own territory and sphere of influence. If someone else rushed into the clan territory, he would be killed, so in the course of time, entry into the land of others meant disaster. But if a brave man did not be killed at one time when he went into other clan territory. Instead, he killed the other person. The warrior would cut off the "head" of the other person as trophies, when entry again into the clan, he would show this "head" to show his power. In the course of time, evil spirits were formed on the territory of other clans, only holding the head could the evil spirits be cleaned. This was the so called Tao.

Here we know the meaning of "Tao". Literally, Tao is the "road". Fundamentally speaking, Tao refers to the "Taoism" in a foreign land full of evil spirits, when holding the "heads" of the other clan passed by, there were no more evil spirits. These had "no evil" was called "Tao". Finally, in essence, there were many roads in the alien land, without carrying head passing through the place, there were many other spirits, it was called "non Tao", when carrying the alien head passing through the place, it was called the Tao". So what is the reason for "road" as "Tao" in essence? The answer is : peace. When enter the alien territory, people were often killed, that was evil, a kind of "fear, anxiety, terror" performance. But when passing by holding the heads of then other clan, it was namely "Tao", there was no evil, but only peace. Professor Zhan Shichuang first noticed this point, he once published the paper On the semanteme of "peace" in Taoist and Taoism[3]. For exploration on the semanteme of "peace" in Taoist and Taoism.

\section{Definition of Taoism Management Thought}

From the above research we know that the core of Taoism management thought is around the "peace" . Home country management, life management, palace view management and ecological management are all pursuing "peace". From the point of view of modern management, the role of managers is focused on five aspects: "plan, organization, personnel, leadership and control". And this is essentially peace, Professor Zeng Shiqiang, the father of Chinese style management, thought that: "The purpose of the plan, in the next few years, how to secure people? " "The function of the 
organization is consistent with the strength of the aggregation of the people." "The significance of leadership is to give full play to the potential of the people. " The purpose of control is to ensure how to secure people in the next few years. "All management measures are closely related to safety people." "Only members of the organization to keep on their own duties, can we make as a whole, and have a strong organizational capacity." "Peace is to combine part and together, to synthesize a whole, and to make the whole larger than the part, and the effect of harmony can be achieved." "the course of peace is a happy journey in minds, and common interest, and then create a series of changes in the minds of us." It has to be said that Professor Zeng specializes in Chinese style management for more than 50 years, which is quite different from other researchers. Most of the other researchers only grasped some details in Chinese traditional culture management thoughts, but Professor Zeng grasped the core problem. The two key points of Taoism management are "man and peace". The subject of management of family \& country is human beings, when all can be well managed, that is, "Taiping". At the same time, "peace" is also a good guidance outline for body, family and country management.

Finally, we can give a definition of "Taoism management thought": Taoism management thought is a philosophy of "An Ping Tai" based on thinking of people, society, nature and universe, the management behavior of life, personal view, family \& country and ecology, which is integrated this kind of "An Ping Tai" philosophy and management behavior to make it theorized and systematized.

\section{References}

[1] Explanation by Lou Yulie, (Wei) Wang Li: Notations on Tao Te Ching. Beijing: Zhong Hua Book Company, 2008, Page 87.

[2] Shira-kawa Kim, translated by Su Bing: Notations to frequently-used characters. Beijing: Kyushu Publishing House, 2010. Page 341.

[3] Zhan Shichuang, Qu Yanfei, On the semanteme of "peace" in Taoist and Taoism. Social Sciences in Chinese colleges and Universities. 2015 (05).

[4] Yu D, Peng L. When does Inferring Reputation Probability Countervail Temptation in Cooperative Behaviors for the Prisoners' Dilemma Game? [J]. Chaos, Solitons \& Fractals, 2015, 78: 238-244. 